\title{
Intention to Pay for HPV Vaccination among Women of Childbearing Age in Vietnam
}

\author{
Xuan Thi Thanh Le ${ }^{1}$, Phuong Thi Ngoc Nguyen ${ }^{1}$, Toan Thi Thanh Do ${ }^{1}{ }^{\mathbb{D}}$, Thang Huu Nguyen ${ }^{1}$, \\ Huong Thi Le ${ }^{1}$, Cuong Tat Nguyen ${ }^{2,3}$, Giang Hai Ha ${ }^{2,4, *}$, Chi Linh Hoang ${ }^{5}$, \\ Bach Xuan Tran ${ }^{1,6}{ }^{(}$, Carl A. Latkin ${ }^{6}{ }^{(0}$, Roger C.M. Ho ${ }^{5,7,8}{ }^{-1}$ and Cyrus S.H. Ho ${ }^{9}$ \\ 1 Institute for Preventive Medicine and Public Health, Hanoi Medical University, Hanoi 100000, Vietnam; \\ lethithanhxuan@hmu.edu.vn (X.T.T.L.); nguyenngocphuong2905@gmail.com (P.T.N.N.); \\ dothithanhtoan@hmu.edu.vn (T.T.T.D.); nguyenhuuthang@hmu.edu.vn (T.H.N.); \\ lethihuong@hmu.edu.vn (H.T.L.); bach.ipmph@gmail.com (B.X.T.) \\ 2 Institute for Global Health Innovations, Duy Tan University, Da Nang 550000, Vietnam; \\ nguyentatcuong@duytan.edu.vn \\ 3 Faculty of Medicine, Duy Tan University, Da Nang 550000, Vietnam \\ 4 Faculty of Pharmacy, Duy Tan University, Da Nang 550000, Vietnam \\ 5 Center of Excellence in Behavioral Medicine, Nguyen Tat Thanh University, \\ Ho Chi Minh City 700000, Vietnam; chi.coentt@gmail.com (C.L.H.); pcmrhcm@nus.edu.sg (R.C.M.H.) \\ 6 Bloomberg School of Public Health, Johns Hopkins University, Baltimore, MD 21205, USA; \\ carl.latkin@jhu.edu \\ 7 Department of Psychological Medicine, Yong Loo Lin School of Medicine, National University of Singapore, \\ Singapore 119228, Singapore \\ 8 Institute for Health Innovation and Technology (iHealthtech), National University of Singapore, \\ Singapore 119077, Singapore \\ 9 Department of Psychological Medicine, National University Hospital, Singapore 119074, Singapore; \\ cyrushosh@gmail.com \\ * Correspondence: hahaigiang@duytan.edu.vn; Tel.: +84-86-9548-561
}

Received: 19 March 2020; Accepted: 20 April 2020; Published: 30 April 2020

Abstract: The intention to pay for human papillomavirus (HPV) vaccination among women of childbearing age in Vietnam, where cervical cancer remains a significant public health concern, has been mostly lacking. To examine this issue, we conducted a cross-sectional study of 807 pregnant women in an urban and a rural district (Dong Da and Ba Vi) of Hanoi, Vietnam. The vast percentage of our respondents expressed a firm intention to vaccinate, especially women in rural areas (over $90.0 \%$ ). However, on being informed of the current price of the HPV vaccine, their intention to vaccinate dropped to about one-fifth of overall respondents, i.e., only $4.4 \%$ of women in rural areas. It was also observed that the initial intention to get the HPV vaccination among women in the rural district was about ten times higher than that of women living in the metropolitan district. Those participants who had greater knowledge of cervical cancer and HPV vaccinations also had a significantly higher intention to vaccinate. Our findings underscore the need to develop a well-designed vaccination program in Vietnam and other countries in a similar situation to increase the adoption of HPV vaccination.

Keywords: HPV vaccination; cervical cancer; intention; women; Vietnam

\section{Introduction}

Cervical cancer is the fourth most common cancer among women worldwide, and the second in developing regions [1]. It remains an enormous global health burden, affecting over 530,000 women and accounting for 270,000 deaths annually. Nearly $84 \%$ of cervical cancer patients and $87 \%$ of related deaths occur in developing parts of the world [1,2]. 
The launch of the human papillomavirus (HPV) vaccination globally in 2006-2007 was a life-saving intervention with the potential to prevent several common and high-risk types of HPV associated with cervical cancer [3]. So far, millions of women have been vaccinated. However, the global uptake of the HPV vaccination has been highly variable, especially in developing parts of the world. Low rates of HPV vaccination were found in Greece [4,5], Hong Kong [6], and Cambodia [7], though most women surveyed in these countries stated a strong intention to vaccinate [8,9]. In Southeast Asia, two-thirds of the women surveyed expressed a strong intention to get the HPV vaccine $[7,10]$ while actual vaccination rates remained low.

To explain the enormous gap between intention and reality, earlier studies highlighted the cost of the vaccine as one of the chief obstacles to the more widespread utilization of the HPV vaccine $[7,9]$. In most developed parts of the world, where HPV vaccination is integrated into existing immunization programs, it is free of charge and not an economic burden for citizens. In less-developed regions, women's intention to vaccinate dropped as soon as they learned they had to pay out of pocket or if the vaccination was considered a deductible [7]. Some studies conducted in Southeast Asia found that when the vaccination was free or priced exceedingly low (around \$5), the rate of vaccination was extremely high [11-14].

Cervical cancer is the second-most-common cancer in women aged 15 to 44 in Vietnam [15]. In 2008, Vietnam conducted the HPV vaccination pilot program that utilized both a school- and community-based approach to increase the rate of vaccinations among children. This two-year pilot program sponsored by the Global Alliance for Vaccines and Immunization targeted 12-year-old girls. Although the pilot achieved a coverage rate of over $96.0 \%$, the HPV vaccine is not included in the national immunization program currently. Compared with the global average cost of about $\$ 400$ for a three-shot series of the HPV vaccine, the price of around \$150-\$195 in Vietnam is exceedingly low. However, this remains out of reach for most Vietnamese citizens, at nearly one-tenth of the average per capita income (about \$2170) in 2016. Obstacles to the uptake of the HPV vaccination include price, parents who do not want to spend lots of money on their daughter (gender inequality), and inadequate knowledge, specifically among parents of the target population and especially in lower-middle-income countries such as Vietnam [16,17].

In this study of the Dong Da and Ba Vi districts of Hanoi, Vietnam, we assessed the intention to pay for HPV vaccination among pregnant women or those who recently gave birth. This is the first study to examine the intention to say yes to HPV vaccination among this specific group, which is important since females of reproductive age often play the role of the principal decision-makers in their families' health care. Moreover, during this particular period, women also have more interest in vaccination programs-understanding their thought process is critical to the design and implementation of successful vaccination programs to increase the acceptance of the HPV vaccination in society and minimize the burden of both HPV and related diseases.

\section{Materials and Methods}

\subsection{Study Setting, Sample Size, and Sampling Method}

A cross-sectional study was conducted from February to June 2016 in two randomly chosen districts, Dong Da (urban) and Ba Vi (rural). These districts were purposely selected since they had experienced an Influenza A or Rubella epidemic in the last five years, had a close consultation with the Hanoi Provincial Health Department and expressed their commitment. Two health communes were selected as study locations based on the following conditions: they (1) had experienced an Influenza A or Rubella epidemic in the past five years; (2) were committed to participating in the study, and (3) had local vaccination policies and vaccines available at each site. These health communes could have more concerns about infectious diseases that could be prevented by our interest vaccination. Finally, a list of all women who were pregnant or who had given birth in the 12 months preceding the survey was collected from the relevant local agencies. 
Since this project covered not only the HPV vaccine but also other vaccines (influenza, hepatitis B, tetanus, and rubella), we chose a study group for whom all these vaccines were relevant-women who were either pregnant or had recently given birth. Eligible participants in the survey were then randomly chosen by the health staff responsible for each cluster in a communal unit.

For sample size calculations, the level of significance was set to 0.05 and the power to $95 \%$, and a two-sided test was utilized. Since there is no preexisting study of the coverage of HPV and other vaccines (influenza, hepatitis B, tetanus, or rubella) among reproductive-aged women in Vietnam, we set up $p=0.5$ to represent the maximum variability of the population [18]. The sample was increased by $10 \%$ in case someone refused to participate or was absent during the collection period. The final sample size was thus about 400 women in each district and 807 in total. Participants were then selected by using a simple random sampling method in two communal health units in Dong Da and Ba Vi from a list of 975 and 470 eligible women, respectively. The interview response rate was $>95 \%$ for both districts.

Participants in a pre-evaluation study were adult women of reproductive age. They were enlisted by village health workers and the community health center staff responsible for managing vaccinations in their communities. These recruited women had to meet the following criteria to be included in the study: (1) aged 18-49 years at the time of the survey; (2) either pregnant or caring for a child under 12 months of age; and (3) currently living in the selected villages for at least one year and present in those villages at the time of the survey.

\subsection{Measures and Instruments}

A structured and face-to-face questionnaire in Vietnamese was used to obtain information on participants' age, education level, current primary occupation, average monthly per capita income, and the current number of children. This questionnaire was developed based on the Vietnamese Ministry of Health's guidelines for preventing infectious diseases and relevant references from the National Institute of Hygiene and Epidemiology [19]. The questionnaire was administered to five pregnant women with children under one year of age in Hanoi, Vietnam, before its utilization in this study. Of note, each item for the measure had alpha reliability greater than 0.6.

In this study, the intention to pay for the HPV vaccine was defined as the intention among unvaccinated women to receive the HPV vaccine after knowing its price. Sociodemographic characteristics measures include age ( $\leq 25 / 26-30 / 31+)$, marital status (with or without a spouse), child-birth status (having infants or pregnant), status of residence (permanent or no/temporary), educational level (high school or less and college or higher), occupation (blue-collar/white-collar/others), monthly household income categorized by the government with the 1,300,000 Vietnam Dong (VND) cut-off point (moderate or poor/near-poor), public health insurance card (yes/no) and self-reported health status (good vs. neutral/not good). Seven detailed questions on cervical cancer or five items on HPV vaccinations were asked of those who had knowledge about either. The detailed findings of these questions are shown in Table S1. One point was given for each correct answer, and the points were summed up to create a summary knowledge score. A high knowledge score means that a participant is relatively knowledgeable about cervical cancer or HPV vaccination. Each summary knowledge score was then divided into two groups: good and not good [20]. Women were categorized in the "good knowledge" group if their score was above the mean, and in the "not good knowledge" group if it was less than the mean. Besides, attitude toward HPV vaccination was measured whether the participants self-assess the vaccination as necessary (positive) or neutral or unnecessary (neutral or negative).

\subsection{Statistical Analysis}

Descriptive analysis was used to assess all sociodemographic variables. Either Pearson's chi-square test or Fisher's exact test (where the expected count for any particular cell is less than 5) was then employed in the bivariate analysis of all categorical variables. A $p$-value of less than 0.05 was considered statistically significant. A logistic regression analysis was used to evaluate the association between the intention to pay for HPV vaccinations and sociodemographic, knowledge-related, and attitudinal 
factors as well; the odds ratios (ORs) and $95 \%$ confidence intervals (CIs) were calculated. The regression models were separately examined by residency status. All statistical analyses were performed using STATA software version 14 (Stata Corp. L.P., College Station, TX, USA).

\subsection{Ethical Considerations}

This study was approved by the Ethics Committee of Hanoi Medical University (Code number: 184/HMU-IRB dated 14 November 2015). Following a face-to-face explanation of the study given by trained healthcare workers at the Hanoi Medical University, all participants gave verbal consent prior to their participation in the study, acknowledging their full understanding of the study's purpose, their rights to withdraw from the study at any time, and the protection and confidentiality of the collected data.

\section{Results}

Table 1 shows the distribution of significant characteristics among participants. A total of 807 participants participated in the study, two-thirds of whom were younger than 30 years. More young women from the rural district (Ba Vi) took part in the survey than from the urban one (Dong Da). Most participants from non-metropolitan areas had lower education levels and were blue-collar workers or peasants. As a result, most of the rural participants were reported to be living in poverty. The coverage of health insurance, therefore, was higher among urban participants, even though there was no difference in health status.

Figure 1 shows the proportion of nonvaccinated women willing to receive the HPV vaccine before and after knowing its price. A considerable percentage of respondents expressed a firm intention to vaccinate, especially in rural areas (over 90.0\%), however, after being informed of the current price of the HPV vaccination, their intentions dropped swiftly to about one-fifth of all respondents and to $4.4 \%$ for women in rural areas.

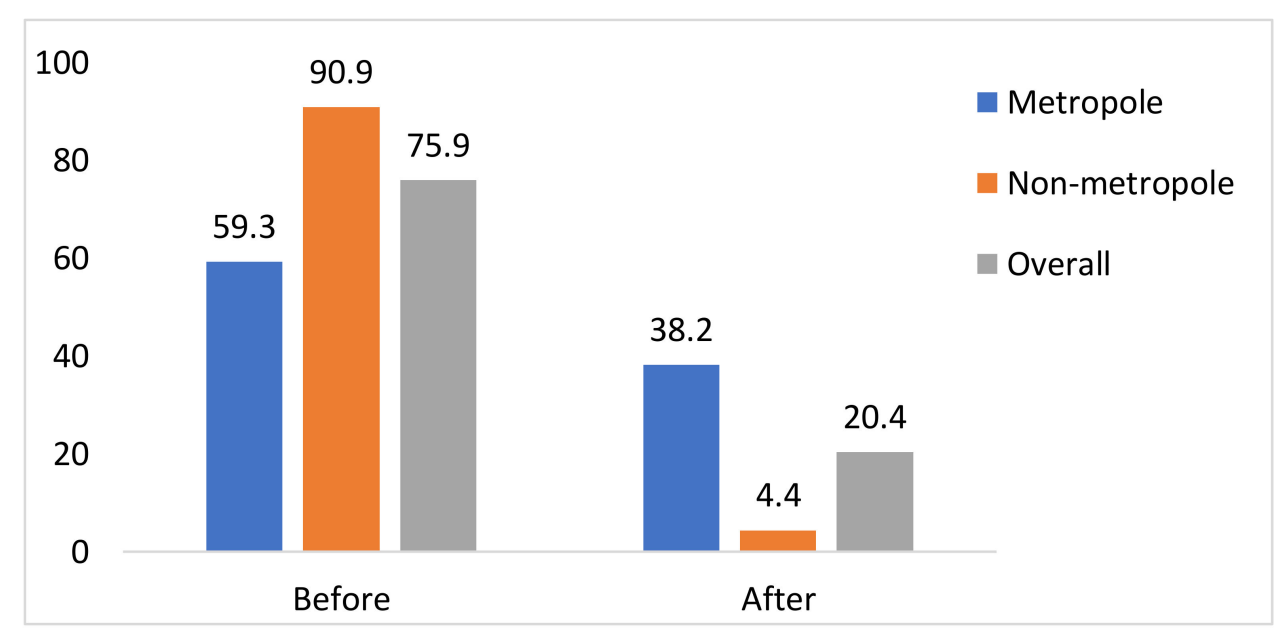

Figure 1. Intention to receive the HPV vaccination before/after knowing the price $(n=769)$.

Table 2 shows participants' intention to get an HPV vaccination before learning its price. Rural females, and even those who lacked knowledge of the benefits of HPV vaccinations, were the most likely to want to get vaccinated. Older women and those with infants, permanent residence, and higher household income had relatively strong intentions to vaccinate. This intention was also seen among women with good knowledge of cervical cancer and a positive attitude toward vaccines. The association between the intention to receive HPV vaccination and monthly household income was significant among participants with both permanent and temporary residency status.

Table 3 demonstrates factors associated with the intention to receive the HPV vaccine (that is, before receiving price information) for unvaccinated women in each subgroup. Overall, women who lived in the countryside had lower educational attainment, were blue-collar workers/peasants, and 
were not covered by health insurance. Of these, those who were temporary residents and relatively older were less likely to want to get vaccinated.

Table 1. Participant's demographic characteristics.

\begin{tabular}{|c|c|c|c|c|c|c|c|}
\hline \multirow{2}{*}{ Variables } & \multicolumn{2}{|c|}{ Overall } & \multicolumn{2}{|c|}{ Urban } & \multicolumn{2}{|c|}{ Rural } & \multirow{3}{*}{$p$-Value ${ }^{1}$} \\
\hline & $n$ & $\%$ & $n$ & $\%$ & $n$ & $\%$ & \\
\hline Total & 807 & 100.0 & 400 & 49.6 & 407 & 50.4 & \\
\hline \multicolumn{8}{|l|}{ Age group } \\
\hline$\leq 25$ years old & 222 & 27.5 & 64 & 16.0 & 158 & 38.8 & \multirow{3}{*}{$<0.001$} \\
\hline 26-30 years old & 302 & 37.4 & 156 & 39.0 & 146 & 35.9 & \\
\hline$>30$ years old & 283 & 35.1 & 180 & 45.0 & 103 & 25.3 & \\
\hline \multicolumn{8}{|l|}{ Marital status } \\
\hline With spouse & 801 & 99.3 & 398 & 99.5 & 403 & 99.0 & \multirow[b]{2}{*}{$0.43^{2}$} \\
\hline Without spouse & 6 & 0.7 & 2 & 0.5 & 4 & 1.0 & \\
\hline \multicolumn{8}{|l|}{ Child-birth status } \\
\hline Having infants ( $0-1$ years) & 609 & 75.5 & 299 & 74.8 & 310 & 76.2 & \multirow{2}{*}{0.64} \\
\hline Pregnant & 198 & 24.5 & 101 & 25.2 & 97 & 23.8 & \\
\hline \multicolumn{8}{|l|}{ Residential status } \\
\hline Permanent residence & 706 & 87.5 & 320 & 80.0 & 386 & 94.8 & \multirow{2}{*}{$<0.001$} \\
\hline Temporary residence & 101 & 12.5 & 80 & 20.0 & 21 & 5.2 & \\
\hline \multicolumn{8}{|l|}{ Educational attainment } \\
\hline College or higher & 424 & 55.5 & 322 & 80.5 & 102 & 25.1 & \multirow{2}{*}{$<0.001$} \\
\hline High school or lower & 383 & 47.5 & 78 & 19.5 & 305 & 74.9 & \\
\hline \multicolumn{8}{|l|}{ Occupation $^{3}$} \\
\hline White collar & 252 & 31.2 & 213 & 53.3 & 39 & 9.6 & \multirow{3}{*}{$<0.001$} \\
\hline Blue collar/Peasants & 284 & 35.2 & 16 & 4.0 & 268 & 65.9 & \\
\hline Others & 271 & 33.6 & 171 & 42.7 & 100 & 24.5 & \\
\hline \multicolumn{8}{|c|}{ Household monthly income per person 4} \\
\hline Moderate or higher & 598 & 74.1 & 382 & 95.5 & 216 & 53.1 & \multirow{2}{*}{$<0.001$} \\
\hline Poor or near poor & 209 & 25.9 & 18 & 4.5 & 191 & 46.9 & \\
\hline \multicolumn{8}{|l|}{ Health insurance card } \\
\hline Yes & 509 & 63.1 & 316 & 79.0 & 193 & 47.4 & \multirow{2}{*}{$<0.001$} \\
\hline No/No response & 298 & 36.9 & 84 & 21.0 & 214 & 52.6 & \\
\hline \multicolumn{8}{|l|}{ Self-reported health status } \\
\hline Good & 502 & 62.2 & 255 & 63.8 & 247 & 60.7 & \multirow{2}{*}{$<0.001$} \\
\hline Central or not good & 305 & 37.8 & 145 & 36.2 & 160 & 39.3 & \\
\hline \multicolumn{8}{|l|}{ Vaccinated with HPV vaccination } \\
\hline Yes & 38 & 4.7 & 36 & 9.0 & 2 & 0.5 & \multirow{2}{*}{$<0.001^{2}$} \\
\hline No & 769 & 95.3 & 364 & 91.0 & 405 & 99.5 & \\
\hline
\end{tabular}

${ }_{1} p$-value was obtained from Pearson's chi-square test. ${ }^{2} p$-value was obtained from Fisher's exact test. ${ }^{3}$ Blue-collar/ peasants: workers in the sales and service sectors, craftspeople, skilled laborers, machine operators, peasants; white-collar: managers, professionals, experts, engineers, office workers; and others: students, unemployed, housewives. ${ }^{4}$ Household income per person was categorized as moderate if the income was $\geq$ VND 1,300,000, or poor/near-poor for the rest.

Table 2. Demographic differences and the intention to vaccinate against HPV (\%).

\begin{tabular}{|c|c|c|c|}
\hline Variable & Overall $(n=769)$ & Metropolitan $(n=364)$ & Nonmetropolitan $(n=405)$ \\
\hline Total & 75.9 & 59.3 & 90.9 \\
\hline \multicolumn{4}{|l|}{ Age } \\
\hline$\leq 25$ years old & 83.3 & 66.1 & 89.8 \\
\hline 26-30 years old & 75.7 & 58 & 91.7 \\
\hline$>30$ years old & 70.4 & 58.1 & 91.3 \\
\hline$p$-value & 0.004 & 0.51 & 0.84 \\
\hline
\end{tabular}


Table 2. Cont.

\begin{tabular}{|c|c|c|c|}
\hline Variable & Overall $(n=769)$ & Metropolitan $(n=364)$ & Nonmetropolitan $(n=405)$ \\
\hline Total & 75.9 & 59.3 & 90.9 \\
\hline \multicolumn{4}{|l|}{ Marriage status } \\
\hline With spouse & 75.9 & 59.1 & 91 \\
\hline Without spouse & 83.3 & 100 & 75 \\
\hline$p$-value & 0.67 & 0.24 & 0.27 \\
\hline \multicolumn{4}{|l|}{ Child-birth status } \\
\hline Having infants $(0-1$ years) & 77.3 & 62.3 & 90.6 \\
\hline Pregnant & 71.8 & 50.6 & 91.8 \\
\hline$p$-value & 0.13 & 0.049 & 0.73 \\
\hline \multicolumn{4}{|l|}{ Residential status } \\
\hline Permanent residence & 77.2 & 59.5 & 90.6 \\
\hline No/Temporary residence & 67 & 58.9 & 95.2 \\
\hline$p$-value & 0.03 & 0.93 & 0.48 \\
\hline \multicolumn{4}{|l|}{ Educational attainment } \\
\hline College or higher & 68.7 & 60.6 & 92 \\
\hline High school or lower & 83.3 & 54.6 & 90.5 \\
\hline$p$-value & $<0.001$ & 0.34 & 0.65 \\
\hline \multicolumn{4}{|l|}{ Occupation ${ }^{1}$} \\
\hline White collar & 65.5 & 60.1 & 92.1 \\
\hline Blue collar/Peasants & 87 & 43.8 & 89.6 \\
\hline Others & 73 & 60 & 93.9 \\
\hline$p$-value & $<0.001$ & 0.43 & 0.42 \\
\hline \multicolumn{4}{|c|}{ Household monthly income per person ${ }^{2}$} \\
\hline Moderate or higher & 73.4 & 59.3 & 96.3 \\
\hline Poor or near poor & 82.8 & 61.1 & 84.8 \\
\hline$p$-value & 0.007 & 0.88 & $<0.001$ \\
\hline \multicolumn{4}{|l|}{ Health insurance card } \\
\hline Yes & 73.3 & 60.4 & 92.2 \\
\hline No/No response & 80.3 & 55.6 & 89.7 \\
\hline$p$-value & 0.03 & 0.43 & 0.38 \\
\hline \multicolumn{4}{|l|}{ Self-reported health status } \\
\hline Good & 75.5 & 59.7 & 90.2 \\
\hline Central or not good & 76.7 & 58.8 & 91.9 \\
\hline$p$-value & 0.7 & 0.88 & 0.57 \\
\hline \multicolumn{4}{|l|}{ Knowledge of cervical cancer ${ }^{3}$} \\
\hline Good & 83.7 & 68.6 & 95.5 \\
\hline Not good & 67.9 & 51 & 85.4 \\
\hline$p$-value & $<0.001$ & 0.001 & $<0.001$ \\
\hline \multicolumn{4}{|l|}{ Knowledge of HPV vaccinations } \\
\hline Good & 81.1 & 71.8 & 92.4 \\
\hline Not good & 72.3 & 47.6 & 90 \\
\hline$p$-value & 0.005 & $<0.001$ & 0.42 \\
\hline \multicolumn{4}{|l|}{ Attitude toward HPV vaccinations } \\
\hline Positive & 82.7 & 69.2 & 93.2 \\
\hline Neutral/negative & 44.4 & 27.1 & 74 \\
\hline$p$-value & $<0.001$ & $<0.001$ & $<0.001$ \\
\hline
\end{tabular}

${ }^{1}$ Blue-collar/peasants: workers in the sales and service sectors, craftspeople, skilled laborers, machine operators, peasants; white-collar: managers, professionals, experts, engineers, office workers; and others: students, unemployed, housewives. ${ }^{2}$ Household income per person was categorized as moderate if the income was $\geq$ VND 1,300,000, or poor/near-poor for the rest. ${ }^{3}$ For those who had heard about cervical cancer/HPV vaccination only.

Among the metropolitan group, those who had adequate knowledge of cervical cancer and HPV vaccination, as well as a positive attitude toward vaccinations, were more likely to want to get vaccinated. 
Table 3. Univariate logistic regression for intention to receive the HPV vaccination.

\begin{tabular}{|c|c|c|c|c|c|c|}
\hline \multirow{2}{*}{ Variables } & \multicolumn{2}{|c|}{ Overall } & \multicolumn{2}{|c|}{ Metropolitan } & \multicolumn{2}{|c|}{ Nonmetropolitan } \\
\hline & $\mathrm{OR}^{1}$ & $95 \% \mathrm{CI}^{2}$ & $\mathrm{OR}^{1}$ & $95 \% \mathrm{CI}^{2}$ & $\mathrm{OR}^{1}$ & $95 \% \mathrm{CI}^{2}$ \\
\hline Location $\left(\right.$ Metropolitan $=\operatorname{ref}^{3}$ ) & 6.81 & $4.58-10.14$ & & & & \\
\hline \multicolumn{7}{|l|}{ Age $(\leq 25$ years old $=$ ref $)$} \\
\hline 26-30 years old & 0.62 & $0.40-0.98$ & 0.71 & $0.37-1.35$ & 1.26 & $0.57-2.76$ \\
\hline$>30$ years old & 0.48 & $0.31-0.74$ & 0.71 & $0.38-1.32$ & 1.19 & $0.50-2.79$ \\
\hline $\begin{array}{l}\text { Residency status } \\
\text { (Permanent residence = ref) }\end{array}$ & 0.60 & $0.38-0.96$ & 0.98 & $0.58-1.65$ & 2.07 & $0.27-15.87$ \\
\hline $\begin{array}{l}\text { Educational attainment } \\
\text { (College or higher = ref) }\end{array}$ & 2.26 & $1.60-3.19$ & 0.78 & $0.47-1.29$ & 0.83 & $0.37-1.87$ \\
\hline $\begin{array}{l}\text { Household monthly income } \\
\text { (Moderate or higher = ref) }\end{array}$ & 1.74 & $1.16-2.61$ & 1.08 & $0.41-2.86$ & 0.22 & $0.10-0.49$ \\
\hline $\begin{array}{l}\text { Health insurance card } \\
\text { (No = ref) }\end{array}$ & 0.67 & $0.47-0.96$ & 1.22 & $0.74-2.01$ & 1.36 & $0.68-2.70$ \\
\hline $\begin{array}{l}\text { Self-reported health status } \\
\text { (No good = ref) }\end{array}$ & 0.94 & $0.66-1.32$ & 1.03 & $0.67-1.59$ & 0.81 & $0.40-1.65$ \\
\hline $\begin{array}{l}\text { Knowledge of cervical cancer } \\
\text { (Not good = ref) }\end{array}$ & 2.42 & $1.71-3.42$ & 2.10 & $1.37-3.22$ & 3.59 & $1.69-7.63$ \\
\hline $\begin{array}{l}\text { Knowledge of HPV vaccinations } \\
\text { (Not good = ref) }\end{array}$ & 1.64 & $1.16-2.32$ & 2.80 & $1.81-4.32$ & 1.35 & $0.65-2.83$ \\
\hline $\begin{array}{l}\text { Attitude toward HPV vaccinations } \\
\text { (Neutral or negative = ref) }\end{array}$ & 5.95 & $4.00-8.86$ & 6.05 & $3.52-10.40$ & 4.85 & $2.28-10.32$ \\
\hline
\end{tabular}

${ }^{1}$ OR: odds ratio ${ }^{2} \mathrm{CI}=$ confidence interval ${ }^{3}$ ref $=$ reference.

In the non-metropolitan group, those who had greater knowledge of and a positive attitude toward HPV vaccination were more likely to want to get vaccinated. However, the more impoverished the household, the weaker the intention to vaccinate.

The multivariable logistics for the intention to receive the HPV vaccine (before knowing its price) among nonvaccinated women are displayed in Table 4 . A strong correlation was noted between location and intention to vaccinate against HPV. Women from poor or near-poor households, especially those in rural areas, were the least likely to want to be vaccinated against HPV. The strongest intention was seen among those with a good knowledge of cervical cancer and HPV vaccinations and a positive attitude.

Table 4. Multivariable logistics for the intention to receive the HPV vaccine ${ }^{1}$.

\begin{tabular}{|c|c|c|c|c|c|c|}
\hline \multirow{2}{*}{ Variables } & \multicolumn{2}{|c|}{ Overall } & \multicolumn{2}{|c|}{ Metropolitan Group } & \multicolumn{2}{|c|}{ Nonmetropolitan Group } \\
\hline & $\mathrm{aOR}^{2}$ & $95 \% \mathrm{CI}^{3}$ & $\mathrm{aOR}^{2}$ & $95 \% \mathrm{CI}^{3}$ & $\mathrm{aOR}^{2}$ & $95 \% \mathrm{CI}^{3}$ \\
\hline Location $\left(\right.$ Metropolitan $=$ ref $^{4}$ ) & 10.53 & $5.58-19.86$ & & & & \\
\hline \multicolumn{7}{|l|}{ Age $(\leq 25$ years old $=$ ref $)$} \\
\hline $26-30$ years old & 0.75 & $0.44-1.29$ & 0.47 & $0.23-0.99$ & 1.50 & $0.64-3.54$ \\
\hline$>30$ years old & 0.79 & $0.47-1.35$ & 0.57 & $0.28-1.15$ & 1.35 & $0.53-3.48$ \\
\hline $\begin{array}{l}\text { Residency status } \\
\text { (Permanent residence = ref) }\end{array}$ & 1.37 & $0.78-2.38$ & 1.37 & $0.75-2.51$ & 3.72 & $0.40-34.44$ \\
\hline $\begin{array}{l}\text { Educational attainment } \\
\text { (College or higher = ref) }\end{array}$ & 1.03 & $0.62-1.71$ & 0.81 & $0.44-1.49$ & 1.68 & $0.65-4.33$ \\
\hline $\begin{array}{l}\text { Household monthly income } \\
\text { (Moderate or higher = ref) }\end{array}$ & 0.48 & $0.26-0.90$ & 1.48 & $0.48-4.58$ & 0.21 & $0.09-0.52$ \\
\hline $\begin{array}{l}\text { Health insurance card } \\
(\mathrm{No}=\text { ref })\end{array}$ & 1.08 & $0.68-1.71$ & 1.09 & $0.60-1.97$ & 1.05 & $0.49-2.25$ \\
\hline
\end{tabular}


Table 4. Cont.

\begin{tabular}{|c|c|c|c|c|c|c|}
\hline \multirow{2}{*}{ Variables } & \multicolumn{2}{|c|}{ Overall } & \multicolumn{2}{|c|}{ Metropolitan Group } & \multicolumn{2}{|c|}{ Nonmetropolitan Group } \\
\hline & $\mathrm{aOR}^{2}$ & $95 \% \mathrm{CI}^{3}$ & $\mathrm{aOR}^{2}$ & $95 \% \mathrm{CI}^{3}$ & $\mathrm{aOR}^{2}$ & $95 \% \mathrm{CI}^{3}$ \\
\hline $\begin{array}{l}\text { Self-reported health status } \\
\text { (No good = ref) }\end{array}$ & 0.84 & $0.56-1.26$ & 0.96 & $0.59-1.56$ & 0.62 & $0.29-1.32$ \\
\hline $\begin{array}{l}\text { Knowledge of cervical cancer } \\
\text { (Not good = ref) }\end{array}$ & 1.72 & $1.14-2.61$ & 1.44 & $0.88-2.36$ & 2.46 & $1.08-5.63$ \\
\hline $\begin{array}{l}\text { Knowledge of HPV vaccinations } \\
\text { (Not good = ref) }\end{array}$ & 1.60 & $1.06-2.42$ & 1.89 & $1.17-3.04$ & 0.89 & $0.39-2.02$ \\
\hline $\begin{array}{l}\text { Attitude toward HPV vaccinations } \\
\text { (Neutral or negative = ref) }\end{array}$ & 4.37 & $2.73-6.98$ & 5.25 & $2.89-9.52$ & 3.62 & $1.51-8.66$ \\
\hline
\end{tabular}

\section{Discussion}

This is the first study to quantitatively investigate the intention to pay for HPV vaccination among women of childbearing age in Vietnam, after controlling for residency status. Cervical cancer remains a significant public health concern in this country. As others have noted, we found that the overwhelming majority of our respondents expressed a strong intention to accept the HPV vaccination $[8,9,21,22]$. However, a drop in this intention was observed after the women learned its price, similar to previous results [8,12,23-25]. Additionally, none of the participants categorized as being from a poor/near-poor household was vaccinated against HPV. It was correspondingly predicted in a PATH study in 2009 that cost could be one of the chief obstacles to the uptake of the HPV vaccine in Vietnam [26]. Diverse studies conducted in developing parts of the world have highlighted high cost as an obstacle to vaccine acceptance [27,28], indicating that economic constraints keep women from taking advantage of this important health service even where it is available. Strategies to promote the HPV vaccine will need to pay particular attention to some key demographic trends. Women with temporary residency status, with relatively low levels of educational attainment, and who come from poor households are the least likely to want to accept the HPV vaccine.

In our study, the intention to accept HPV vaccination was about ten times higher among rural women (Figure 1) than among urban women after knowing the price, corroborating findings from populations in 2016 [29]. This could be because the rural participants did not take the price into account. Our data also clearly demonstrated the difference in their intention before and after knowing the price. The intention to vaccinate dropped quickly from more than almost all rural women to less than $5 \%$ before and after knowing the price. In Vietnam, the vaccine against HPV was promoted using the name "cervical cancer vaccine" to emphasize the goal of cervical cancer prevention [26]. In prior studies, rural women were found to have a higher cervical cancer rate, so they might correspondingly have had greater concern about cervical cancer and are more interested in its prevention [29-31].

Our study received strong support from local health workers in each collection unit. The relationship between physicians and communities may be more robust in the countryside in comparison with urban zones, as cited in a recent US study [29]. Therefore, rural women, who are more likely to trust their health workers could agree to this vaccination more easily, even though nearly half of them had not heard of it before participating in our survey.

As foreseen, the results clearly show that those with preexisting knowledge of cervical cancer and HPV vaccinations also had significantly greater intention to get vaccinated. This is in line with another study observing that people's level of knowledge appears to significantly influence their intention to vaccinate [4-6,32-35]. The "health belief model" has been utilized widely to justify several predictors of potential vaccine uptake [36]. According to this model, women with less knowledge of cervical cancer and HPV vaccinations are believed to have a lower perception of the risks and severity of an HPV infection and of the benefits of the HPV vaccine, which may lead to their lower intention of getting vaccinated against HPV [36]. Further, as a decade has gone by since the approval of the HPV 
vaccine, it might be assumed that information about it has been spread widely during this period and has generated a more positive attitude among women toward the vaccine. Thus, knowledge of cervical cancer/HPV vaccinations is changing behavior and increasing the number of women getting vaccinated $[35,37]$.

Some existing limitations of the present study may affect the interpretation of our findings. First, data were employed in a cross-sectional study in the pre-evaluation in 2016, so it is beyond the scope of the present study to determine any causal relationship. Second, participants in this study (women of childbearing age) were mainly out of the recommended age for HPV vaccination (9-26 years old). Thus, their intention to vaccinate themselves could be quite low compared to their intention to vaccinate their daughters. To deal with this limitation, we recommend that their intention to vaccinate their daughters against HPV be queried in the post-evaluation phase. Lastly, this study only focused on women of pregnancy or child-birth age; thus, our result may not be representative of the entire population of women.

Despite these limitations, our study has several strengths. It is the first study to investigate the association between several factors and the intention to get vaccinated against HPV among women of childbearing age in Vietnam. The findings could call for public health policy to implement a step-by-step strategy for cervical cancer prevention. The study sample of women of childbearing age, a child's primary caretaker and health keeper for each family is also a strength. As others have stated, decisions regarding vaccines, including against HPV, are primarily made by the mother; other family members play either a small role or no role at all $[16,17]$. Mothers' intentions to vaccinate themselves and their daughters against HPV could be sharply limited due to a lack of knowledge about cervical cancer and HPV vaccinations. Therefore, the most important thing to do is to understand and improve parental knowledge about HPV vaccination and tackle obstacles to its future uptake.

Collectively, based on the present findings, education programs would do well to build on existing knowledge, focusing on women (and particularly mothers), while simultaneously addressing common misconceptions. Since knowledge is a necessary precursor for health-protective behaviors, including the decision to get vaccinated, addressing knowledge gaps may enable people to make better choices. Further, education campaigns (including the vaccine's promotion via leaflets) should take advantage of community health centers, where rural women go to get general vaccinations. Also, to deal with the high cost of this expensive vaccine, a two-dose schedule should be carefully considered, and the cost reduced to at least one-third of the current price to make it affordable. Further, integration of this vaccination into our national immunization program should be taken into the government's consideration since it could be a life-saving vaccine for the public. The two-dose schedule and public tenders could lead to important price rebate opportunities.

Looking ahead, a qualitative study is needed to better understand women's outlook on the HPV vaccine and the particular obstacles to vaccination in Vietnam.

\section{Conclusions}

An overwhelming majority of study respondents (women of childbearing age) expressed a strong intention to get vaccinated against HPV across both urban and rural areas of Hanoi, the capital of Vietnam. However, a quick drop in the intention to vaccinate was observed once these same women were informed of the vaccine price. Our findings thus underscore the need to develop a well-designed vaccination program in Vietnam and other countries in a similar situation to increase the uptake of HPV vaccination.

Supplementary Materials: The following are available online at http://www.mdpi.com/1660-4601/17/9/3144/s1, Table S1: Knowledge of cervical cancer and HPV vaccine questions.

Author Contributions: Conceptualization, X.T.T.L., T.H.N., G.H.H., C.A.L., R.C.M.H., and C.S.H.H.; Data curation, P.T.N.N., T.T.T.D., T.H.N., and B.X.T.; Formal analysis, X.T.T.L., C.T.N., C.L.H., and C.A.L.; Funding acquisition, C.T.N., and B.X.T.; Investigation, X.T.T.L., P.N.T.N., T.T.T.D., H.T.L., and R.C.M.H.; Methodology, P.T.N.N., H.T.L., C.T.N., G.H.H., C.L.H., B.X.T., and C.A.L.; Project administration, C.S.H.H.; Resources, C.T.N., C.L.H. and B.X.T.; 
Software, P.N.T.N.; Supervision, R.C.M.H. and C.S.H.H.; Validation, T.T.T.D., T.H.N., and G.H.H.; Visualization, H.T.L.; Writing—original draft, X.T.T.L.; Writing—review \& editing, T.T.T.D., T.H.N., H.T.L., G.H.H., C.L.H., C.A.L., R.C.M.H., and C.S.H.H. All authors have read and agreed to the published version of the manuscript.

Funding: This research received no external funding.

Acknowledgments: We thank Karen Eggleston and the Stanford Asia Health Policy Program for comments on an earlier draft.

Conflicts of Interest: The authors declare no conflict of interest.

\section{References}

1. Ferlay, J.; SI, E.M.; Dikshit, R.; Eser, S.; Mathers, C.; Rebelo, M.; Parkin, D.M.; Forman, D.; Bray, F. Globocan 2012: Cervical Cancer: Estimated Incidence, Mortality and Prevalence Worldwide. International Agency for Ressearch on Cancer (IARC). Available online: http://globocan.iarc.fr/old/FactSheets/cancers/cervix-new.asp (accessed on 10 November 2019).

2. Organization W.H. Human Papillomavirus (HPV) and Cervical Cancer. Available online: http://www.who. int/mediacentre/factsheets/fs380/en/ (accessed on 10 November 2019).

3. World Health Organization. Human Papillomavirus (HPV). Available online: https://www.who.int/ immunization/diseases/hpv/en/ (accessed on 8 March 2019).

4. Donadiki, E.M.; Jimenez-Garcia, R.; Hernandez-Barrera, V.; Carrasco-Garrido, P.; Lopez de Andres, A.; Jimenez-Trujillo, I.; Velonakis, E.G. Knowledge of the HPV vaccine and its association with vaccine uptake among female higher-education students in Greece. Hum. Vaccines Immunother. 2013, 9, 300-305. [CrossRef]

5. Jelastopulu, E.; Fafliora, E.; Plota, A.; Babalis, V.; Bartsokas, C.; Poulas, K.; Plotas, P. Knowledge, behaviours and attitudes regarding HPV infection and its prevention in female students in West Greece. Eur. Rev. Med. Pharmacol. Sci. 2016, 20, 2622-2629.

6. Chiang, V.C.; Wong, H.T.; Yeung, P.C.; Choi, Y.K.; Fok, M.S.; Mak, O.I.; Wong, H.Y.; Wong, K.H.; Wong, S.Y.; Wong, Y.S.; et al. Attitude, Acceptability and Knowledge of HPV Vaccination among Local University Students in Hong Kong. Int. J. Environ. Res. Public Health 2016, 13, 486. [CrossRef] [PubMed]

7. Touch, S.; Oh, J.K. Knowledge, attitudes, and practices toward cervical cancer prevention among women in Kampong Speu Province, Cambodia. BMC Cancer 2018, 18, 294. [CrossRef] [PubMed]

8. Li, J.; Li, L.K.; Ma, J.F.; Wei, L.H.; Niyazi, M.; Li, C.Q.; Xu, A.D.; Wang, J.B.; Liang, H.; Belinson, J.; et al. Knowledge and attitudes about human papillomavirus (HPV) and HPV vaccines among women living in metropolitan and rural regions of China. Vaccine 2009, 27, 1210-1215. [CrossRef] [PubMed]

9. Chan, Z.C.; Chan, T.S.; Ng, K.K.; Wong, M.L. A systematic review of literature about women's knowledge and attitudes toward human papillomavirus (HPV) vaccination. Public Health Nurs. 2012, 29, 481-489. [CrossRef] [PubMed]

10. Wong, L.P. Knowledge and attitudes about HPV infection, HPV vaccination, and cervical cancer among rural southeast Asian women. Int. J. Behav. Med. 2011, 18, 105-111. [CrossRef] [PubMed]

11. Kruiroongroj, S.; Chaikledkaew, U.; Thavorncharoensap, M. Knowledge, acceptance, and willingness to pay for human papilloma virus (HPV) vaccination among female parents in Thailand. Asian Pac. J. Cancer Prev. 2014, 15, 5469-5474. [CrossRef]

12. Hong, Y.; Zhang, C.; Li, X.; Lin, D.; Liu, Y. HPV and cervical cancer related knowledge, awareness and testing behaviors in a community sample of female sex workers in China. BMC Public Health 2013, 13, 696. [CrossRef]

13. Tonguc, E.; Gungor, T.; Var, T.; Kavak, E.; Yucel, M.; Uzunlar, O. Knowledge about HPV, relation between $\mathrm{HPV}$ and cervix cancer and acceptance of HPV vaccine in women in eastern region of Turkey. J. Gynecol. Oncol. 2013, 24, 7-13. [CrossRef]

14. Vietnam National Institute of Hygiene and Epidemiology and PATH. Evaluating HPV Vaccine Delivery Strategies in Vietnam; PATH: Seattle, WA, USA, 2010.

15. Bruni, L.; Barrionuevo-Rosas, L.; Albero, G.; Serrano, B.; Mena, M.; Gómez, D.; Muñoz, J.; Bosch, F.X.; de Sanjosé, S. Human Papillomavirus and Related Diseases Report; ICO/IARC Information Centre on HPV and Cancer (HPV Information Centre): Barcelona, Spain, 2017. 
16. Tung, I.L.; Machalek, D.A.; Garland, S.M. Attitudes, knowledge and factors associated with human papillomavirus (hpv) vaccine uptake in adolescent girls and young women in Victoria, Australia. PLoS ONE 2016, 11, e0161846. [CrossRef] [PubMed]

17. Bingham, A.; Drake, J.K.; LaMontagne, D.S. Sociocultural issues in the introduction of human papillomavirus vaccine in low-resource settings. Arch. Pediatr. Adolesc. Med. 2009, 163, 455-461. [CrossRef] [PubMed]

18. Pourhoseingholi, M.A.; Vahedi, M.; Rahimzadeh, M. Sample size calculation in medical studies. Gastroenterol. Hepatol. Bed Bench 2013, 6, 14-17. [PubMed]

19. Vietnam Ministry of Health. Guidelines on the Implementation of Infection Control in Health Care Institutions; Vietnam Ministry of Health: Hanoi, Vietnam, 2009.

20. Prayudi, P.K.; Permatasari, A.A.; Winata, I.G.; Suwiyoga, K. Impact of human papilloma virus vaccination on adolescent knowledge, perception of sexual risk and need for safer sexual behaviors in Bali, Indonesia. J. Obstet. Gynaecol. Res. 2016, 42, 1829-1838. [CrossRef] [PubMed]

21. Dursun, P.; Altuntas, B.; Kuscu, E.; Ayhan, A. Women's knowledge about human papillomavirus and their acceptance of HPV vaccine. Aust. N. Z. J. Obstet. Gynaecol. 2009, 49, 202-206. [CrossRef]

22. Islam, J.Y.; Khatun, F.; Alam, A.; Sultana, F.; Bhuiyan, A.; Alam, N.; Reichenbach, L.; Marions, L.; Rahman, M.; Nahar, Q. Knowledge of cervical cancer and HPV vaccine in Bangladeshi women: A population based, cross-sectional study. BMC Women's Health 2018, 18, 15. [CrossRef]

23. Liu, F.W.; Vwalika, B.; Hacker, M.R.; Allen, S.; Awtrey, C.S. Cervical cancer and HPV vaccination: Knowledge and attitudes of adult women in Lusaka, Zambia. J. Vaccines Vaccin. 2012, 3, 6816. [CrossRef]

24. Songthap, A.; Pitisuttithum, P.; Kaewkungwal, J.; Fungladda, W.; Bussaratid, V. Knowledge, attitudes, and acceptability of a human papilloma virus vaccine among students, parents and teachers in Thailand. Southeast Asian J. Trop. Med. Public Health 2012, 43, 340-353.

25. Zhao, F.H.; Tiggelaar, S.M.; Hu, S.Y.; Zhao, N.; Hong, Y.; Niyazi, M.; Gao, X.H.; Ju, L.R.; Zhang, L.Q.; Feng, X.X.; et al. A multi-center survey of HPV knowledge and attitudes toward HPV vaccination among women, government officials, and medical personnel in China. Asian Pac. J. Cancer Prev. 2012, 13, 2369-2378. [CrossRef]

26. Vietnam National Institute of Hygiene and Epidemiology and PATH. Shaping a Strategy to Introduce HPV vaccines in Vietnam: Formative Research Results; HPV Vaccines/Evidence for Impact Project: Ho Chi Minh City, Vietnam, 2009.

27. Wong, L.P. Issues surrounding HPV vaccine delivery in a multi-ethnic country in Asia: The physician's perspective. J. Community Health 2011, 36, 14-22. [CrossRef]

28. Rambout, L.; Tashkandi, M.; Hopkins, L.; Tricco, A.C. Self-reported barriers and facilitators to preventive human papillomavirus vaccination among adolescent girls and young women: A systematic review. Prev. Med. 2014, 58, 22-32. [CrossRef] [PubMed]

29. Monnat, S.M.; Rhubart, D.C.; Wallington, S.F. Differences in human papillomavirus vaccination among adolescent girls in metropolitan versus non-metropolitan areas: Considering the moderating roles of maternal socioeconomic status and health care access. Matern. Child Health J. 2016, 20, 315-325. [CrossRef] [PubMed]

30. Benard, V.B.; Johnson, C.J.; Thompson, T.D.; Roland, K.B.; Lai, S.M.; Cokkinides, V.; Tangka, F.; Hawkins, N.A.; Lawson, H.; Weir, H.K. Examining the association between socioeconomic status and potential human papillomavirus-associated cancers. Cancer 2008, 113, 2910-2918. [CrossRef] [PubMed]

31. Baker, P.; Hoel, D.; Mohr, L.; Lipsitz, S.; Lackland, D. Racial, age, and rural/urban disparity in cervical cancer incidence. Ann. Epidemiol. 2000, 10, 466-467. [CrossRef]

32. Bendik, M.K.; Mayo, R.M.; Parker, V.G. Knowledge, perceptions, and motivations related to HPV vaccination among college women. J. Cancer Educ. 2011, 26, 459-464. [CrossRef]

33. Feng, S.; Xu, X.; Jin, Y.; Yao, X. Women's knowledge of human papillomavirus (HPV) and their attitudes toward HPV vaccine: Preparing for HPV vaccination in China. Asia Pac. J. Public Health 2012, 24, 522-531. [CrossRef]

34. Fernandez, M.E.; Le, Y.C.; Fernandez-Espada, N.; Calo, W.A.; Savas, L.S.; Velez, C.; Aragon, A.P.; Colon-Lopez, V. Knowledge, attitudes, and beliefs about human papillomavirus (HPV) vaccination among Puerto Rican mothers and daughters, 2010: A qualitative study. Prev. Chronic Dis. 2014, 11, E212. [CrossRef]

35. Janz, N.K.; Becker, M.H. The Health Belief Model: A decade later. Health Educ. Q. 1984, 11, 1-47. [CrossRef] 
36. Kaliyaperumal, K. Guideline for conducting a knowledge attitude and practice (KAP) study. AECS Illum. 2004, 4, 7-9.

37. Vandamme, E. Concepts and challenges in the use of knowledge-attitude-practice surveys: Literature review. Dep. Anim. Health Instit. Instit. Trop. Med. Antwerp. 2009, 1, 1-7.

(C) 2020 by the authors. Licensee MDPI, Basel, Switzerland. This article is an open access article distributed under the terms and conditions of the Creative Commons Attribution (CC BY) license (http://creativecommons.org/licenses/by/4.0/). 